Rakenteiden Mekaniikka (Journal of Structural Mechanics)

Vol. 50, No 3, 2017, pp. 326-329

https://rakenteidenmekaniikka.journal.fi/index

https:/doi.org/10.23998/rm.65153

(c)Author(s) 2017.

Open access under CC BY-SA 4.0 license.

\title{
Optimum design of welded structures
}

Károly Jármai

Summary. This article presents the cost calculation system developed by us to determine the cost of a welded structure. In the paper the design, fabrication and economy are linked together in the optimization system. Two tubular truss applications show, that the reduction of cost can be significant.

Key words: welded structures, optimization, mathematical methods

Received 4 July 2017. Accepted 17 August 2017. Published online 21 August 2017.

\section{Introduction}

The main requirements of modern welded metal structures are load-carrying capacity (safety), fitness for production, and economy. Safety and fitness for production are guaranteed by fulfilling the design and fabrication constraints. The economy is achieved by minimizing the cost function.

These cost calculations are founded on material costs and those fabrication costs, which have a direct effect on the sizes, dimensions or shape of the structure. The cost function includes the cost of material, assembly, welding as well as surface preparation, painting and cutting, edge grinding, forming the shell and is formulated according to the fabrication sequence. Other costs, like amortization, investment, transportation, maintenance are not considered here. Cost and production time data come from different companies from all over the world. When we compare the same design at different countries, we should consider the differences between labour costs. It has the most impact on the structure, if the technology is the same. This Chapter describes the cost calculations of the different technologies. These costs are the objective functions in structural optimization. 


\section{The cost function}

The cost function of a real structure may include the cost of material, assembly, the different fabrication costs such as welding, surface preparation, painting and cutting, edge grinding, forming the geometry, etc.

The cost of materials can be given as

$$
K_{M}=k_{M} \rho V .
$$

For steel the specific material cost can be $k_{M}=1.0-1.3 \$ / \mathrm{kg}$, for aluminium $k_{M}=3.0-3.5$ $\$ / \mathrm{kg}$, for stainless steel $k_{M}=6.0-7.1 \$ / \mathrm{kg}$, for glass fibre $20-30 \$ / \mathrm{m}^{2}$ depending on the thickness. $K_{M}[\mathrm{~kg}]$ is the fabrication cost, $k_{M}[\$ / \mathrm{kg}]$ is the corresponding material cost factor, $V\left[\mathrm{~mm}^{3}\right]$ is the volume of the structure, $\rho$ is the density of the material. For steel it is $7.85 \times 10^{-6} \mathrm{~kg} / \mathrm{mm}^{3}$, for aluminium $2.7 \times 10^{-6} \mathrm{~kg} / \mathrm{mm}^{3}$. If several different materials are used, then it is possible to use different material cost factors simultaneously in Eq. (1).

In general, the fabrication costs could be written as a linear function

$$
K_{f}=k_{f} \sum_{i} T_{i},
$$

where $K_{f}[\$]$ is the fabrication cost, $k_{f}$ [\$/min] is the corresponding fabrication cost factor, $T_{i}[\mathrm{~min}]$ are production times. It is assumed that the value of $k_{f}$ is constant for a given manufacturer. If not, it is possible to apply different fabrication cost factors simultaneously in Eq. (9).

The main times related to welding are as follows: preparation, assembly, tacking, time of welding, changing the electrode, deslagging and chipping.

The times of preparation, assembly and tacking can be calculated with an approximation formula as follows

$$
T_{w 1}=C_{1} \Theta_{d w} \sqrt{\kappa \rho V},
$$

where $C_{1}$ is a parameter depending on the welding technology (usually equal to 1 ), $\Theta d w$ is a difficulty factor, $\kappa$ is the number of structural elements to be assembled. The difficulty factor expresses the complexity of the structure. Difficulty factor values depend on the kind of structure (planar, spatial), the kind of members (flat, tubular). The range of values proposed is between 1-4 [1].

Real welding time can be calculated in the following way

$$
T_{w 2}=\sum_{i} C_{2 i} a_{w i}^{2} L_{w i},
$$

where $a_{w i}$ is weld size, $L_{w i}$ is weld length, $C_{2 i}$ is constant for different welding technologies. $C_{2}$ contains not only the differences between welding technologies, but the time differences between positional (vertical, overhead) and normal welding in downhand position as well. The equations for different welding technologies can be found in the [1].

There are some additional fabrication actions to be considered such as changing the electrode, deslagging and chipping. The approximation of this time is as follows (Table 1) 


$$
T_{w 3}=0.3 \sum C_{2 i} a_{w i}^{n} L_{w i} \text {. }
$$

Table 1. Welding times $T_{\mathrm{w} 2}(\mathrm{~min} / \mathrm{mm})$ in the function of weld size $a_{w}(\mathrm{~mm})$ for longitudinal fillet welds, downhand position

\begin{tabular}{ccc}
\hline Welding technology & $a_{w}[\mathrm{~mm}]$ & $10^{3} T_{w 2}=10^{3} C_{2} a_{w}^{2}$ \\
\hline SMAW, Shielded Metal Arc Welding & $0-15$ & $0.7889 a_{w}^{2}$ \\
\hline SMAW HR, Shielded Metal Arc Welding High Recovery & $0-15$ & $0.5390 a_{w}^{2}$ \\
\hline GMAW-C, Gas Metal Arc Welding with $\mathrm{CO}_{2}$ & $0-15$ & $0.3394 a_{w}^{2}$ \\
\hline GMAW-M, Gas Metal Arc Welding with Mixed Gas & $0-15$ & $0.3258 a_{w}^{2}$ \\
\hline FCAW, Flux Cored Arc Welding & $0-15$ & $0.2302 a_{w}^{2}$ \\
\hline FCAW-MC, Metal Cored Arc Welding & $0-15$ & $0.4520 a_{w}^{2}$ \\
\hline SSFCAW (ISW) Self Shielded Flux Cored Arc Welding & $0-15$ & $0.2090 a_{w}^{2}$ \\
\hline SAW, Submerged Arc Welding & $0-15$ & $0.2349 a_{w}^{2}$
\end{tabular}

In is proportional to $T_{w 2}$. It is the $30 \%$ of it. The two time elements are as follows:

$$
T_{w 2}+T_{w 3}=1.3 \sum C_{2 i} a_{w i}^{n} L_{w i} \text {. }
$$

The welding times for $1 / 2 \mathrm{~V}, \mathrm{~V}, \mathrm{~K}$ and $\mathrm{X}$ welding are as follows for the different technologies our book [11].

\section{Application for different welded tubular trusses}

We have made the optimization of different tubular structures. Optimizing with parallel and non-parallel chords, the structures are different. The comparison of the trusses with parallel and non-parallel chords shows that the structural volume of the truss with nonparallel chords is $12 \%$ smaller than that of truss with parallel chords, i.e. the second version is more economic Figs. 1 and 2.

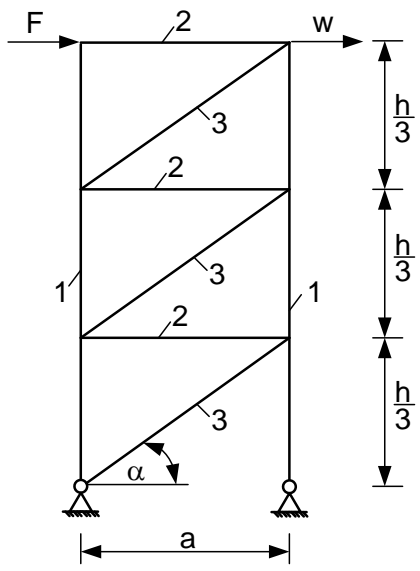

Fig. 1. A tubular truss with parallel chords

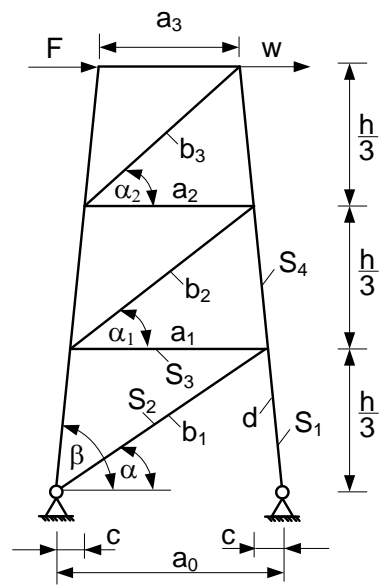

Fig. 2. A tubular truss with non-parallel chords 
Optimizing the N-type truss with parallel chords and the rhombic-type truss with parallel chords gives different solutions. The volume and cost minima are smaller for rhombic-type truss, both in the case of stress and deflection constraint. In the case of stress constraint this difference is $100(10.55-6.973) / 10.55=34 \%$ in volume and $20 \%$ in cost. In the case of deflection constraint this difference is $37 \%$ in volume and $29 \%$ in cost Figs. 3 and 4.

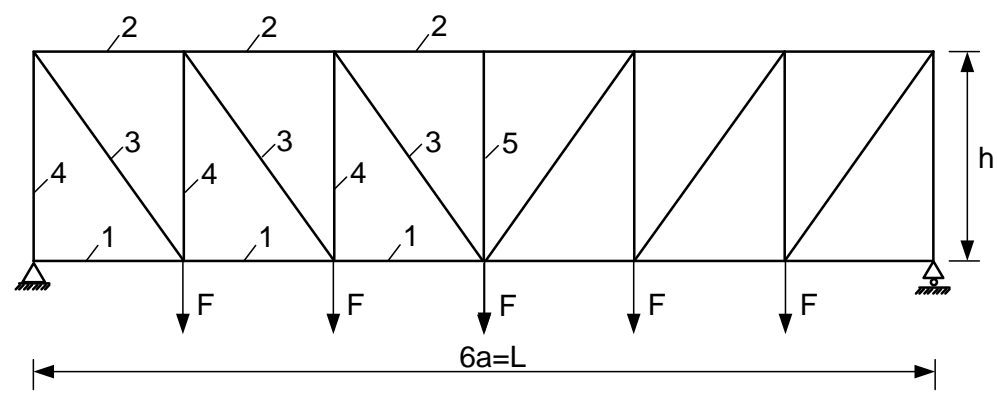

Fig. 3. N-type truss with parallel chords, numbering of rod groups

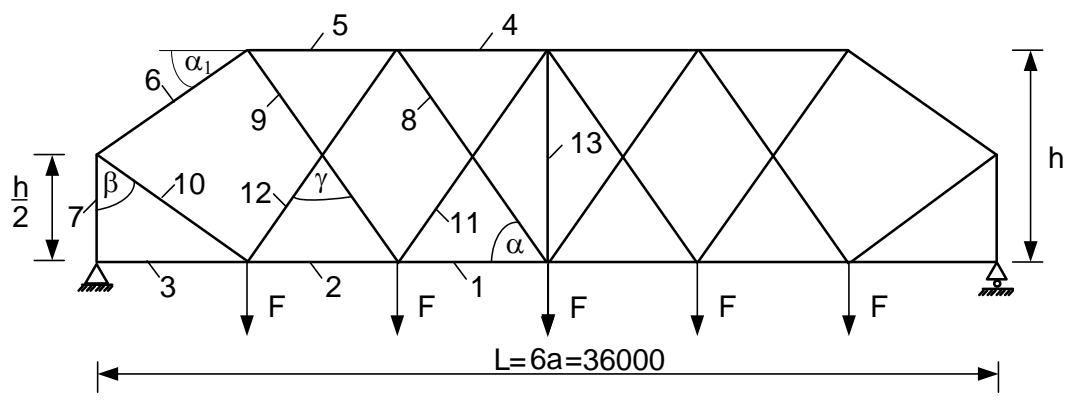

Fig. 4. Rhombic-type truss with parallel chords

\section{Acknowledgement}

The research was supported by the Hungarian Scientific Research Fund OTKA T 109860 project.

\section{References}

[1] Farkas,J.,Jármai,K.: Optimum design of steel structures, Springer Verlag, Heidelberg, 2013. 288 p. ISBN 978-3-642-36867-7, http://dx.doi.org/10.1007/978-3-642-36868-4

[2] EN 1993-1-1 Eurocode 3 "Design of steel structures. Part 1-3: General rules and rules for buildings”. CEN, 2008.

Károly Jármai

University of Miskolc

H-3515 Miskolc, Egyetemvaros, Hungary

altjar@uni-miskolc.hu 